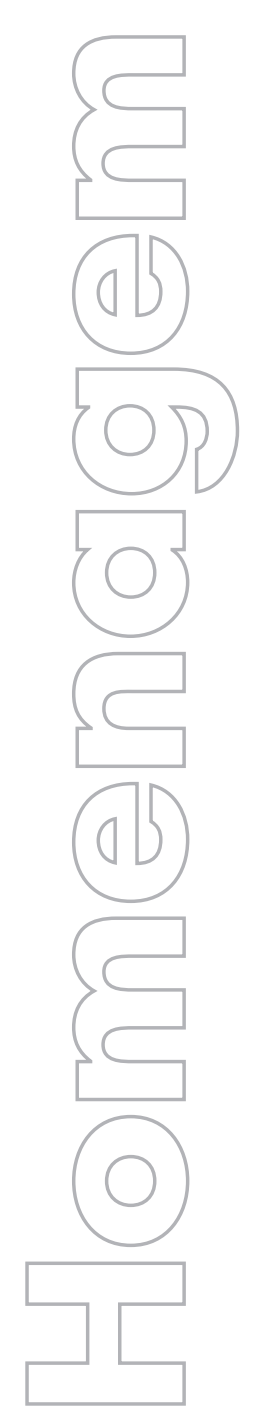

revista

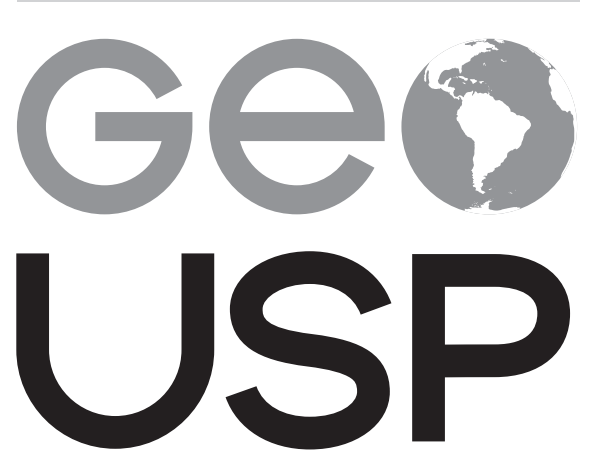

espaço e tempo

Volume $23 \cdot n^{\circ} 2$ (2019)

ISSN 2179-0892

\section{Pensar a cidade} é pensar o país.

Francisco de Oliveira: um biógrafo não autorizado do Brasil

\author{
Cibele Saliba Rizek
}

Universidade de São Paulo - Brasil

p. $226-241$

Como citar este artigo:

RIZEK, C. S. Pensar a cidade é pensar o país. Francisco de Oliveira: um biógrafo não autorizado do Brasil. Geousp Espaço e Tempo (Online), v. 23, n. 2, p. 226-241, ago. 2019. ISSN 2179-0892.

Disponível em: https://www.revistas.usp.br/geousp/article/ view/161108. doi: https://doi.org/10.11606/issn.2179-0892. geousp.2019.161108.

\section{(c) (i) (8)}

Este artigo está licenciado sob a Creative Commons Attribution 4.0 License. 


\section{Pensar a cidade é pensar o país. Francisco de Oliveira: um biógrafo não autorizado do Brasil ${ }^{1}$}

Cibele Saliba Rizek

Ao meu mestre e amigo Chico de Oliveira, um biógrafo não autorizado do Brasil Com saudade, respeito e admiração

Certa tarde, no Centro de Estudos dos Direitos da Cidadania, a discussão sobre o governo brasileiro produziu uma polarização interessante: de um lado, os "otimistas", de outro, os "pessimistas", capitaneados por Chico de Oliveira, esse biógrafo não autorizado do Brasil. Já no final do impasse, que aliás não se resolveu, Chico-naquele momento ainda marcado pelas idas e vindas do lulismo - me disse: "Querida, você sabe o que é um otimista? Um pessimista malinformado".

Diante do que vivemos nestes tempos sombrios, afinal, era Chico quem tinha razão.

\section{Introdução}

Como as cidades aparecem na produção de Chico de Oliveira? Quais as chaves que ele nos dá para discuti-las? Como se podem pensar hoje esses territórios que materializam o que Oliveira enunciava já a partir de 2003 como Estado de exceção? Os textos, livros e ensaios de Francisco de Oliveira nunca nos levaram a respostas fáceis. Aprender com ele e conviver com suas inquietações talvez seja sempre aprender a construir questões, ganhar densidade, reler perguntas em novas chaves, encontrar armadilhas, tornando complexo o que aparece de modo simplificado na produção e na recepção sociológica e política brasileiras.

A resposta às questões da cidade em suas especificidades brasileiras pode ser construída a partir de três pistas que oferecem alguns fios, que, entrelaçados permitem traçar um percurso explicativo. $\bigcirc$ primeiro fio vem de Crítica à razão dualista, de 1972, reeditado em 2003; em seguida, há um outro fio que nasce de Estado e urbano no Brasil, de 1982, e, finalmente, aqueles que podem ser puxados dos ensaios que analisam um período que se inicia nos anos 1990 se estendendo até o presente, anos marcados por reviravoltas, por reinvenções, por uma discussão em torno dos sentidos da democracia, ${ }^{2}$ tão mais importante quanto mais se constata a fragilidade, a corda bamba da democracia brasileira - permanentemente incompleta, permanentemente ameaçada de muitos modos.

1 Referência ao livro publicado pela Boitempo Brasil, Uma biografia não autorizada. A origem deste artigo é um seminário realizado pelo Grupo Teoria Urbana Crítica no IEA-USP em 2018, que se abria com uma homenagem a Francisco de Oliveira. Agradeço a Ana Fani Carlos o incentivo e o impulso para rever textos anteriores nesta última homenagem a um mestre e um amigo do coração.

2 Esse é o título do livro organizado por Francisco de Oliveira e Maria Célia Paoli que condensa as contribuições do seminário realizado em 1997 pelo então Núcleo de Estudos dos Direitos da Cidadania. Ver Oliveira e Paoli (1999). 
Há diferenças entre estes momentos que permitem desenhar uma trajetória que caminha por questões diversas entre si, provenientes de modos também distintos de enunciar a sociedade e a política no Brasil. Esses modos de enunciação, de certo modo, acompanharam o desdobramento da história socioeconômica e sociopolítica brasileira. Reler esses textos (o próprio Chico os releu e reescreveu em $\bigcirc$ ornitorrinco, por exemplo) é, no mínimo, também um exercício pelo qual é possível perceber que os olhos que os percorrem e os sentidos que ganham já não são os mesmos. Os processos e elementos explicativos ganham novas roupagens, algumas décadas mais tarde, já que se redesenham significados impossíveis de serem apreendidos nas longínquas décadas de 1970-80, quando o futuro democrático brasileiro acenava com promessas que não se cumpriram ou que foram sendo silenciosamente esvaziadas.

\section{Primeiro momento: a crítica da razão dualista}

Do ponto de vista da questão urbana, pode-se identificar uma primeira discussão que se configurava na polêmica em torno do caráter e do sentido da Revolução Burguesa no Brasil ao longo dos primeiros anos da década de $1970 .^{3}$

As cidades - lugar da modernização e da política, do visível e do público - davam forma a uma modernidade tensa e difícil e a um arcaico que se reproduzia como exigência mesma do moderno, na periferia do capitalismo. A chave dessa leitura foi a compreensão dos processos de acumulação do capital e de suas especificidades no Brasil - o que permitiria iluminar os cantos obscuros que as teorias da modernização não conseguiam desvendar. Da agricultura familiar ao mutirão, dos "terciários inchados" às dimensões demográficas, as cidades brasileiras se articulavam de outro modo, a partir de elementos que Francisco de Oliveira - com ousadia sempre sensível - teria reunido para discutir a tese - no mínimo comprometida com uma postura política que mais tarde pôde ser desvelada - de que o Golpe de 1964 teria se constituído como revolução burguesa no Brasil.

As casas autoconstruídas - a casa própria, na linguagem do fetiche burguês ${ }^{4}$-, a pequena agricultura de Minas Gerais, combinada a seus bancos poderosos, à industrialização e à presença do Estado, pedaços de sua experiência vivida ${ }^{5}$ que ganhavam nexo numa reflexão

3 Crítica à razão dualista foi escrito em resposta a outro texto de Fernando Henrique Cardoso a respeito do caráter do golpe de 1964, identificado com um processo que poderia ser caracterizado como uma Revolução Burguesa. A esse respeito, uma entrevista concedida por Francisco de Oliveira à autora em fevereiro de 2001 traça o percurso dessa discussão no âmbito do Centro Brasileiro de Análise e Planejamento (Cebrap). A esse respeito, ver também o depoimento de Paul Singer (1972).

4 Referência à linguagem utilizada por Francisco de Oliveira e Crítica à razão dualista.

$5 \mathrm{Na}$ mesma entrevista concedida à autora, Francisco de Oliveira relata um dos momentos de inquietação descritos no texto. A junção da agricultura de subsistência com os grandes capitais dos bancos de Minas Gerais começava a se configurar como desafio, como mistério a ser desvendado. Nas palavras de Chico: "Mas eu fui bancário este tempo todo, né? E os bancos mais fortes do Brasil, com exceção, evidentemente, do Banco do Brasil, eram os bancos de Minas, o Banco da Lavoura de Minas Gerais, que é um banco fortíssimo. O Banco Nacional veio a ser forte depois, nos anos 1960; na época em que eu trabalhei, ele era, na verdade... mal era mencionado. Mas havia dois ou três bancos em Minas com os pés fincados na agricultura mais atrasada, porque a agricultura de Minas era tão ou mais atrasada que a do Nordeste, a agricultura de Minas... esses bancos todos eu conheci porque eles já tinham filiais no Nordeste quando eu era bancário, aos 14 anos. Quer dizer, há muito tempo. Não havia nenhum banco de São Paulo, por exemplo, no Nordeste todo. O que existia era o Banco do Brasil e os bancos de Minas, não é? Aí, eu disse: 'Esse treco é misterioso. De onde é que vem esse capital bancário, onde ele está fincado?'. Por isso, eu fui estudar as relações entre indústria e agricultura, primeiramente, do ponto de vista macroeconômico. Então, segui através de indicadores de preços, de indicadores de crescimento. Depois foi que eu matei a charada, ou achei que matava a charada, com a questão do 
inédita e original, encontravam lugar num empreendimento que alertava contra leituras até então quase inquestionáveis, pela junção sempre complicada entre Estado, classes, indústria, modernidade e atraso, cidade e campo.

A Crítica à razão dualista se construiu no interior de um embate teórico e político, flagrando sinais que, alinhavados, apontavam uma nova forma de explicação. Seus fundamentos em sólida fidelidade a Marx se assentavam num conjunto de considerações que articulavam acumulação e reprodução ampliada do capital em suas especificidades na periferia do capitalismo. A partir dessas especificidades, Mestre Chico apontava a fusão permanentemente reposta entre acumulação primitiva e acumulação capitalista, para um desenvolvimento desigual e combinado cujo horizonte punha em xeque - pelo lugar e pela compreensão das relações de trabalho e produção - todo um universo de soluções explicativas que se constituíam a partir da modernização, do subdesenvolvimento ou da dependência. No centro da explicação estavam a constituição histórica das relações de classe e de expropriação, as formas da dominação política e do Estado, na junção entre as dinâmicas da economia e da política, interpelando uma instância pela outra. Seu caráter ousado, sua originalidade, continuariam a provocar discussões e polêmicas, por décadas. Essas discussões se desdobraram na análise dos mutirões - espontâneos ou não, "autogeridos" ou não - que ainda está viva em dissertações, textos, teses, livros que discutem os mecanismos de autoconstrução, ora como problema ora como solução. Esse mesmo veio crítico poderia ser estendido às relações entre agricultura e indústria, bem como às relações entre produção da agricultura familiar e agronegócio e ainda aos processos que transformaram as relações entre cidade e campo no Brasil, isto é, aos processos que constituíram o Brasil urbano.

A Crítica à razão dualista anteciparia a compreensão da perenidade e continuidade de uma acumulação primitiva ou originária que vem recebendo um conjunto de novos nomes como acumulação por despossessão ou por espoliação - matriz continuamente reposta da produção capitalista no Brasil. No texto, Chico reconhecia a simbiose e organicidade do moderno capitalista e do arcaico pré capitalista, em uma unidade de contrários assentada, na verdade, na expansão do capitalismo, ou seja, numa formação capitalista e não simplesmente num momento histórico de seu processo de constituição reconhecível como subdesenvolvimento. Era então preciso enfatizar as estruturas de dominação que se articulavam de modo endógeno aos processos de acumulação próprios de países como o Brasil e, assim, à sua estrutura de classes..

Nesse feixe de processos de transformação, a Crítica chamava atenção para a centralidade da legislação trabalhista no processo de acumulação a partir dos anos 1930.6 Essa centralidade acaba apontando a limitação estrutural do que se poderia reconhecer como mercado livre de trabalho no Brasil. A legislação trabalhista "interpretou o salário-mínimo rigorosamente como 'salário de subsistência' [...]". $\bigcirc$ decisivo é que as leis trabalhistas fazem parte de um

custo de reprodução da força de trabalho. Através das coisas do IBGE, eu vi a composição da cesta de consumo dos trabalhadores, dos trabalhadores industriais; à época, a composição da cesta de consumo dos trabalhadores industriais numa cidade como São Paulo ainda tinha um forte componente da agricultura camponesa. Basicamente, a alimentação era vinda da agricultura atrasada; quer dizer, farinha de mandioca, desde logo, feijão, arroz... Arroz era uma cultura mais difícil, mais complicada, mas, assim mesmo [...]".

6 Dessa perspectiva, também deveríamos perguntar sobre as relações que precisam ser estabelecidas pela reforma da CLT em 2017, no momento pós-golpe, tanto do ponto de vista político como do ponto de vista das suas relações com novos e velhos padrões de acumulação e reprodução do capital. 
conjunto de medidas destinadas a instaurar um novo modo de acumulação. Para tanto, a população em geral, e especialmente a população que afluía às cidades, precisava ser transformada em "exército de reserva". E Chico advertia: "a regulamentação das leis do trabalho operou a reconversão a um denominador comum de todas as categorias, com o que, antes de prejudicar a acumulação, beneficiou-a" (Oliveira, 2003a, p. 37). Esse impulso transmitido à acumulação caracterizaria uma nova etapa de crescimento da economia brasileira.

segundo aspecto refere-se à intervenção do Estado na esfera econômica, operando na regulamentação dos outros fatores, para além do trabalho (preços; distribuição dos ganhos e perdas entre os diversos estratos ou grupos das classes; gasto fiscal). Seu papel nesse âmbito era o de criar as bases para a acumulação capitalista industrial e sua reprodução no nível das próprias empresas. Os "preços sociais" podem ter financiamento público ou podem simplesmente resultar da imposição de uma distribuição de ganhos entre os grupos sociais, e a direção dessas medidas e processos e de sua condução era a de fazer a empresa capitalista industrial a unidade mais rentável do conjunto da economia.

terceiro aspecto que ganhava relevo dentro do processo da nova articulação - à época caracterizada como desenvolvimentista e populista - referia-se ao papel da agricultura: por seu subsetor de produtos destinados ao consumo interno, a agricultura deveria suprir as necessidades das massas urbanas de forma a manter baixo o custo da alimentação e, secundariamente, o custo das matérias-primas. Assim, a agricultura não se poderia constituir em obstáculo à constituição e à centralidade do processo de acumulação urbano-industrial. Esse era, portanto, o nexo e o ponto nevrálgico de todo o processo. ${ }^{7}$ Em torno dele giraria a estabilidade do todo. Dessa articulação dependeria a viabilidade do processo de acumulação pela empresa capitalista industrial que se assentava numa ampla expansão do "exército industrial de reserva". A solução ao chamado "problema agrário" nos anos da "passagem" da economia de base agrário-exportadora para urbano-industrial foi um ponto fundamental para a reprodução das condições da expansão capitalista. Esse complexo de soluções se apoiariam no enorme contingente de mão de obra, na oferta elástica de terras e viabilização do encontro desses dois fatores pela ação do Estado construindo infraestrutura, principalmente a rede rodoviária. "Ela é um complexo de soluções cujo denominador comum reside na permanente expansão horizontal da ocupação com baixíssimos coeficientes de capitalização e até sem nenhuma capitalização prévia; numa palavra, opera como uma sorte de 'acumulação primitiva'” (Oliveira, 2003a, p. 43).

A introdução do conceito de acumulação primitiva porém, exigia redefinições: "a acumulação primitiva não se dá apenas na gênese do capitalismo: sob certas condições especificas, principalmente quando esse capitalismo cresce por elaboração de periferias, a acumulação primitiva é estrutural e não apenas genética" (Oliveira, 2003a, p. 43).

Explicitavam-se, então, os vínculos entre a produção de gêneros alimentícios e um rebaixamento do seu valor, contribuindo para a centralidade do processo de acumulação do capi-

7 Dessa perspectiva, caberia reexaminar a rearticulação contemporânea entre os diferentes setores para perceber o processo que transforma o agronegócio e as atividades de mineração nova alavanca de uma acumulação que poderia ser caracterizada a partir da hegemonia do capital financeiro num rearranjo que desloca e desfoca as dimensões econômicas à época caracterizadas como nacionais. Cabe ainda apontar os deslizamentos e as reconfigurações das questões relativas ao desenvolvimento e ao desenvolvimentismo, bem como as reconfigurações das questões relativas aos populismos contemporâneos. 
tal nas indústrias e nas cidades. $\bigcirc$ que estava em questão era, então, o custo de reprodução da força de trabalho urbana, ao lado da formação de um proletariado rural que serviria às culturas comerciais de mercado interno e externo. Teria havido uma conciliação entre o crescimento industrial e o agrícola, já que a criação de um mercado urbano e industrial, que teria imposto um tratamento de discriminação e de confisco sobre a agricultura, oferecia como contrapartida a manutenção de um padrão "primitivo" nas atividades agrícolas que tinha por base as altas taxas de exploração da força de trabalho. $\bigcirc$ padrão "primitivo" seria então mantido, ampliado e combinado às novas relações de produção o que teve nas cidades e nas empresas industriais fortes repercussões, permitindo um extraordinário crescimento industrial e dos serviços.

Dois elementos dessa combinação foram especialmente significativos: a constituição de um enorme exército industrial de reserva que incidiria na redefinição das relações capital-trabalho, ampliando as possibilidades de acumulação industrial; a constituição de um padrão de fornecimento de excedentes alimentícios cujo preço era determinado pelo custo de reprodução da força de trabalho rural:

Em outras palavras, o preço de oferta da força de trabalho urbana se compunha basicamente de dois elementos: custo da alimentação - determinado este pelo custo de reprodução da força de trabalho rural - e custo dos bens e serviços propriamente urbanos; nestes, ponderava fortemente uma estranha forma de "economia de subsistência" urbana [...] forçando para baixo o preço de oferta da força de trabalho urbana e, conseqüentemente, os salários reais (Oliveira, 2003a, p. 46).

A equação urbano-industrial e a construção da sua centralidade no processo de acumulação teria ainda um outro elemento: os chamados "serviços" como um conjunto heterogêneo de atividades, cuja única homogeneidade consistiria na característica de não produzirem bens materiais. A hipótese formulada sobre os serviços tinha por base um outro conjunto de elementos e apontamentos críticos e dizia respeito às características específicas da economia brasileira: "o Terciário configura-se, assim, como o setor que mais absorveu os incrementos da força de trabalho". Se essa absorção podia ser creditada à incapacidade do setor primário de reter população e, por oposição, à impossibilidade de absorção pelo setor industrial, Chico oferece como explicação a ideia de que:

[...] o crescimento do Terciário, na forma em que se dá, absorvendo crescentemente a força de trabalho, [...], faz parte do modo de acumulação urbano adequado à expansão do sistema capitalista no Brasil; não se está em presença de nenhuma "inchação", nem de nenhum segmento "marginal" da economia (Oliveira, 2003a, p. 54).

crescimento industrial brasileiro, assentado numa acumulação pobre, teria produzido, com exceção de alguns núcleos mais importantes, as cidades brasileiras que "não passavam de acanhados burgos", lugares em que o crescimento e a expansão da indústria teriam que se centrar na empresa. Nela estava toda a virtualidade da acumulação propriamente capitalista. Mas essa acumulação não se poderia desenvolver sem o apoio de serviços, diferenciados e 
desligados da unidade produtiva propriamente dita. Essa carência teria gerado, num primeiro momento da industrialização, uma "autarquização das unidades fabris" (Oliveira, 2003a, p. 55) a ser substituída pela complexificação da divisão do trabalho, para além dos muros das fábricas: Logo em seguida, com a continuidade da expansão industrial, esta vai compatibilizar-se com a ausência de acumulação capitalística prévia, [...] reproduzindo nas cidades um tipo de crescimento horizontal, extensivo, de baixíssimos coeficientes de capitalização, em que a função de produção sustenta-se basicamente na abundância de mão-de-obra. Assiste-se, inclusive, a revivescência de formas de produção artesanais, principalmente nos chamados serviços de reparação (oficinas, de todos os tipos) (Oliveira, 2003a, p. 55).

A aceleração do crescimento nucleado pela indústria exigiu das cidades infraestrutura e serviços que não existiam, e a intensidade da expansão industrial não permitiria "uma intensa e simultânea capitalização nos serviços", sob pena de esses concorrerem com a indústria propriamente dita pelos escassos fundos disponíveis para a acumulação propriamente capitalística". Em vez de um terciário inchado:

[... trata-se de um tipo de crescimento para esse setor - o dos serviços em geral - que não é contraditório com a forma de acumulação, que não é obstáculo à expansão global da economia, que não é consumidor de excedente [...] a aparência de "inchação" esconde um mecanismo fundamental da acumulação: os serviços realizados à base de pura força de trabalho, que é remunerada a níveis baixíssimos, transferem, permanentemente, para as atividades econômicas de corte capitalista, uma fração do seu valor, "mais-valia" em síntese. Não é estranha a simbiose entre a "moderna" agricultura de frutas, hortaliças e outros produtos de granja com o comércio ambulante? Os serviços de mecânica ou os serviços pessoais, esses tipos de serviços, longe de serem excrescências e apenas depósito do "exército industrial de reserva" são adequados para o processo da acumulação global e da expansão capitalista, e, por seu lado, reforçam a tendência à concentração da renda. Fala-se de urbanização sem industrialização e do seu xipófago, uma urbanização com marginalização. Ora, o processo de crescimento das cidades brasileiras - para falar apenas do nosso universo - não pode ser entendido senão dentro de um marco teórico onde as necessidades da acumulação impõem um crescimento dos serviços horizontalizado, cuja forma aparente é o caos das cidade (Oliveira, 2003a, p. 59).

Já que o crescimento urbano anárquico não seria caótico em relação às necessidades da acumulação, Chico foi mostrando que, "mesmo uma certa fração da acumulação urbana, durante o longo período de liquidação da economia pré-anos 1930, revela formas do que se poderia chamar, audazmente, de 'acumulação primitiva"' (Oliveira, 2003a, p. 27).

Daí decorrem suas teses sobre o mutirão - aquilo que hoje chamaríamos de autoprovisão de habitação por meio da casa própria e da forma de ajuda mútua que gerou e ainda gera tanta tensão e discussão. Chico afirmava então que "uma operação que é, na aparência, uma 
sobrevivência de práticas de 'economia natural' dentro das cidades, casa-se admiravelmente bem com um processo de expansão capitalista, que tem uma de suas bases e seu dinamismo na intensa exploração da força de trabalho" (Oliveira, 2003a, p. 59). Desenhava-se assim, dentro da lógica intersetorial assim como dentro das dimensões industriais e urbanas, o que Chico reconhece como desenvolvimento desigual e combinado. A tese original e insuperável é a da introdução de relações novas nos contextos arcaicos pela reprodução de relações arcaicas no novo. Em função de uma compatibilização com a acumulação do capital e seus circuitos, as novas relações no arcaico liberariam força de trabalho que suportariam a acumulação industrial e urbana assim como a reprodução de relações arcaicas no novo preservariam o potencial de cumulação liberado com a finalidade de expandir o próprio novo. Esses processos combinados teriam sido necessários à expansão industrial, ao longo de uma transição radical de uma acumulação quase inteiramente dependente do setor externo para uma acumulação cujo eixo se transformava no setor interno da economia brasileira. Ao longo dessa transição, concentraram-se renda, propriedade e poder.

Desse modo, apontava mestre Chico, o processo de formação da economia brasileira pode ser entendido como a história "da expansão da economia capitalista [...] mas esta expansão não repete nem reproduz [...] o modelo clássico do capitalismo nos países mais desenvolvidos, nem a estrutura que é o seu resultado." Assim:

[...] tomando como um dado a inserção e a filiação da economia brasileira ao sistema capitalista, sua transformação estrutural, nos moldes do processo pós-anos 30, passa a ser, predominantemente, uma possibilidade definida dentro dela mesma; isto é, as relações de produção vigentes continham em si a possibilidade de reestruturação global do sistema, aprofundando a estruturação capitalista, ainda quando o esquema da divisão internacional do trabalho no próprio sistema capitalista mundial fosse adverso. Nisso reside uma diferenciação da tese básica da dependência, que somente vê essa possibilidade quando há sincronia entre os movimentos interno e externo (Oliveira, 2003a, p. 61).

Esses elementos que podem ser tomados como as grandes linhas de força da análise de Crítica à razão dualista desembocariam na questão e na discussão da Revolução Burguesa no Brasil, tema que emergia de tensões, possibilidades e transformações no modo de acumulação, na estrutura de poder e no modo de dominação.

\section{Segundo momento: o Estado e o urbano}

Dez anos mais tarde, outra discussão seria retomada em Estado e urbano no Brasil - a autarquização das cidades brasileiras, processo correlato a um modo de dominação também autarquizado ou autocrático, marcado pelas relações entre Estado e sociedade civil no contexto brasileiro.

A atualidade de sua conclusão pode ser atestada recuperando suas palavras:

[...] [a investigação] do urbano e das relações entre Estado e urbano requer uma pesquisa essencial sobre essas relações entre Estado e sociedade civil e sobre as 
contradições de interesses que formam agora dois blocos que, além dos antagonismos do ponto de vista da produção social da riqueza, apresentam um antagonismo do pondo de vista de como direcionar e utilizar o aparelho de Estado (Oliveira, 1982, p. 54).

Assim, as relações entre Estado e urbano no Brasil, tematizadas a partir da divisão social do trabalho, seriam questionadas do ângulo das relações de produção e de sua regulação, temas que já compareciam em Crítica à razão dualista e seriam retomados mais tarde. Esta mesma relação com o Estado ganhava visibilidade no espaço das cidades (Oliveira, 1982, p. 37). No percurso deste texto, alguns pressupostos históricos foram recuperados a partir da economia colonial e, assim, das dimensões rurais que permitiam a inserção do Brasil na divisão internacional do trabalho. As cidades e sua localização litorânea (tantas vezes apontada desde as explicações brasileiras dos anos 1930) estariam ancoradas nestas determinações e mediações e, por consequência, na "forma específica do capital que controlava desde cima (sem entrar nela) essa economia agroexportadora". Nas cidades, localizaram-se os aparelhos do Estado português e, posteriormente, brasileiro, o que as conformava como suas sedes privilegiadas. Essas cidades, cujo caráter burocrático não poderia ser negado, foram também a sede do capital comercial, o que "responde, na maioria dos casos, pelo caráter que a urbanização toma, por exemplo, no Brasil colônia e depois, já com o país independente, [...] na expansão da agricultura de exportação [...], até o final dos anos vinte" (Oliveira, 1982, p. 37).

Se a industrialização redefine o papel e o caráter das cidades, por outro lado, este caráter urbano enraizado na colônia não teria sido compreendido até o fim, dando margem, no Brasil e em toda América Latina, "à teorização sobre a inchação, a famosa urbanização sem industrialização, marginalidade social e aspectos correlatos" (Oliveira, 1982, p. 38).

Estes temas, na formulação de 1982, enfatizavam o caráter da produção agrária brasileira do qual não poderia nascer uma rede urbana importante, ainda que dele se originassem as grandes cidades brasileiras. Uma rede urbana pobre e, ao mesmo tempo, polarizada, produzida e reproduzida a partir destes padrões, marcaria o caráter do fenômeno urbano no Brasil, pelo menos até a década de 1920. Lado a lado com esses resultados históricos, as cidades foram apontadas como sede dos:

[...] movimentos políticos batizados pela história brasileira como "revoluções" [...]. As cidades, enquanto sede do capital comercial, começam a criar uma série de contradições entre esses capitais [...] fundados no controle da produção agrícola e na intermediação com a circulação nacional de mercadorias (Oliveira, 1982, p. 39/40).

Desses elementos decorre um caráter autárquico das produções para exportação que encolhia e embotava a divisão social do trabalho. Na raiz dessa forma embotada de divisão social do trabalho estavam a escravidão e suas relações com o conjunto da economia, que truncavam o processo de formação de um mercado de trabalho, tornando-se a chave para a compreensão da pobreza e da polarização da rede urbana. Assim, o urbano e os processos e relações de trabalho estariam inextrincavelmente articulados. 
Se os vínculos entre industrialização e urbanização são óbvios, o outro lado da moeda permanecia obscuro:

A pergunta que se coloca é por que a industrialização, quando se dá, impõe um ritmo de urbanização desse porte? Aí, o que se pode fazer é contrapor a antiga autarquia do campo, que determinava um caráter pobre de urbanização no conjunto do país, à autarquia das cidades [que,] ao tornarem-se com a industrialização o centro do aparelho produtivo, vão, pela própria herança do padrão anterior, constituir-se em cidades autárquica (Oliveira, 1982, p. 41).

$\bigcirc$ novo padrão de acumulação potencializava uma urbanização superior ao ritmo da industrialização, imediatamente e excepcionalmente urbana, já que não podia se apoiar em nenhuma divisão do trabalho pretérita no interior das unidades agrícolas (Oliveira, 1982, p. 42).

Desses pressupostos analíticos decorre a crítica ácida às teorias que indicavam uma urbanização sem industrialização, de que decorreriam o "inchaço e a "marginalidade social" configurada como componente dos exércitos industriais de reserva, que F. de Oliveira dissociava da exclusão do mercado de trabalho ou da exclusão da economia urbana. Retomando mais uma vez a Crítica à razão dualista, apontava que esses elementos indicam "a forma peculiar pela qual a industrialização brasileira trouxe para dentro de si, de uma só vez [...] todo esse exército industrial de reserva, vindo dos campos para dentro das cidades" (Oliveira, 1982, p. 43). Essa autarquização se estendia ainda para as unidades industriais constituídas sob a forma patrimonial. Essa mesma forma autárquica incidiria ainda no ritmo de crescimento urbano pós 1930, determinando um processo de capitalização e acumulação dessa indústria a taxas excepcionalmente altas. Essa é a base material de uma forma que moldaria tanto a "famosa dependência" econômica em relação ao capital internacional quanto um padrão de acumulação urbana, "múltiplo da acumulação industrial", que conduziria o Estado a direcionar a potência de seu poder de coerção extraeconômica para a mudança do padrão de acumulação. Disso resultaria "a [...] transposição de excedentes de uns grupos sociais para outros, penalizando a produção agroexportadora e direcionando os seus mecanismos e os seus aparelhos para potenciar a acumulação industrial". Assim:

[...] do ponto de vista das relações de produção, este novo urbano, ou melhor, a relação entre o Estado e o Urbano, consiste no aspecto mais crucial, que é precisamente a regulamentação das relações entre capital e trabalho; e a Revolução burguesa no Brasil nasce com uma aparência contraditória em relação ao que classicamente se tem entendido como sendo a Revolução burguesa nos países centrais (Oliveira, 1982, p. 44).

Deste modo, na contramão da afirmação das liberdades, a Revolução burguesa brasileira, em seu caráter autocrático, conforme a análise de Florestan Fernandes, negaria estas mesmas liberdades individuais, regulando as relações entre a propriedade do capital e o uso do trabalho. Também negaria certas liberdades das antigas oligarquias regionais, centralizando poderes de regulação das atividades econômicas, legislando sobre o comércio interno e externo e, finalmente, afirmando a capacidade de uma burguesia industrial emergente de constituir um espaço econômico nacional unificado que, por assim dizer, permitiria e estimularia a circulação de mercadorias e, consequentemente, o processo de acumulação. Neste contexto pós trinta, 
afirmava F. de Oliveira, "o urbano é essa intervenção do Estado nas relações capital-trabalho, criando, com isso, pela primeira vez, um mercado de trabalho - ou um mercado de força de trabalho" (Oliveira, 1982, p. 45), permitindo a fixação de um preço da força de trabalho potencialmente homogeneizadora, viabilizando a constituição de um cálculo burguês. Neste processo de transferência de excedentes, o Estado articularia esse novo processo de acumulação que é industrial e simultânea e necessariamente urbano (Oliveira, 1982, p. 47).

A partir dos anos 1950, com a presença do investimento público nos espaços que constituíram um setor produtivo estatal, a partir da contradição entre os processos de industrialização da periferia e a dinâmica dos centros do capitalismo, o Estado passaria a assumir tarefas que a burguesia nacional não era capaz de cumprir, quer por causa dos padrões tecnológicos superiores à própria capacidade de acumulação, quer pela própria autarquização que a industrialização havia imposto às cidades. Socializando perdas e privatizando lucros, ${ }^{8}$ o Estado centralizaria capitais, anunciando o que Oliveira qualificava, naquele momento, como capitalismo monopolista. As dimensões de uma nova divisão internacional do trabalho, determinada por um conjunto de processos econômicos em âmbito mundial, aliada à debilidade da burguesia brasileira, conformariam um momento da industrialização que se constituiria em espaço privilegiado de expansão das empresas internacionais. Nesse momento, o Estado teria se conformado como sujeito do processo de centralização dos capitais.

O crescimento dos trabalhadores improdutivos identificados com as "classes médias", uma fração operária relativamente pequena e um enorme contingente de trabalhadores na reserva teriam consequências significativas para a chamada "questão urbana". Oliveira identificava, então, dois elementos: as dimensões urbanas destas classes médias, por um lado, e sua constituição em uma das bases do autoritarismo brasileiro, por outro?.

No contexto da ditadura militar, a partir do silenciamento das classes trabalhadoras, que viram truncadas suas formas de organização econômica e política:

[...] o Estado passa, do ponto de vista dos investimentos e do gasto público, a atender sobretudo às demandas das classes médias que estão nas cidades, criando esse paradoxo de que uma cidade como São Paulo, cujo orçamento é o terceiro do país [...] seja dinamicamente incapaz de atender às demandas que vêm das classes sociais mais baixas [...]. $\bigcirc$ urbano, de certa forma, é hoje a expressão da forma de organização da atividade econômica, de um lado, que cria uma certa estrutura de classes e, do outro lado, do regime político, da falta de voz das classes populares, direcionando, portanto, os gastos do Estado, todo o seu poder [...] para atender sobretudo aos reclamos advindos das demandas das classes médias (Oliveira, 1982, p. 54).

8 A expressão que identifica a socialização das perdas e a privatização dos lucros como um processo constantemente renovado na política econômica brasileira é de Celso Furtado (2009[1959]).

9 Francisco de Oliveira se referia ao apoio de parcelas das classes médias urbanas à instauração e manutenção dos governos militares do período 1964-1985. Assim, seria possível perceber o entrelaçamento entre a dinâmica econômica, a produção e reprodução do urbano e os desdobramentos e entrelaçamentos políticos do país. Talvez no contexto no novo autoritarismo brasileiro essas relações precisassem ser restabelecidas a partir de um novo conjunto de mediações e determinações que permitam um solo explicativo e, talvez, o desenho de um novo cenário de possibilidades. 
Nas palavras de F. de Oliveira, plenamente compreendidas só muito mais tarde:

[...] a pesquisa do urbano e das relações entre Estado e urbano requer uma pesquisa essencial sobre essas relações entre Estado e sociedade civil e sobre as contradições de interesses que formam agora dois blocos que, além dos antagonismos do ponto de vista da produção social da riqueza, apresentam um antagonismo do pondo de vista de como direcionar e utilizar o aparelho de Estado (Oliveira, 1982, p. 54).

\section{Terceiro momento: o Estado de exceção e sua materialidade urbana}

Na produção mais recente de Chico, uma dimensão implacável de denúncia do rebaixamento dos horizontes de expectativa, de um embotamento da reflexão, de um conformar-se ao real como única alternativa ganha novas cores nas descrições da cidade, que se faz presente por meio de temas que ora se colocam na perspectiva da materialização da desigualdade (o que remete sem dúvida à questão da pobreza nominada como terciário inchado ou como marginalidade e marginalização nos anos 1970-80) ora apontam possibilidades de reinvenção da política, ora o silenciamento, por modos e mecanismos distintos daqueles que caracterizaram a ditadura militar, das classes e camadas populares.

Nos diagnósticos recentes, da segunda metade dos anos 1990 até hoje, as questões se complicam mais uma vez: políticas sociais, que funcionalizaram, despolitizaram e empreenderam a gestão e a administração da pobreza, e políticas públicas, que ganharam forma a partir dos direitos do antivalor (Oliveira, 1998) - base material das possibilidades de universalização, desmercantilização da vida - se embaralharam, perderam distinção. Práticas e novas justificativas recobertas de um novo discurso teórico acabaram por recobrir de "normalidade" e legitimidade uma crescente mercantilização de direitos que se configuravam anteriormente como horizontes universais. Esses novos dispositivos insidiosamente destituem conquistas de direitos, reinstaurando um espaço da necessidade onde não há lei, onde se verifica a suspensão da lei, um Estado de exceção, uma exceção permanente, que se teria se implantado por meio de processos inéditos de privatização da vida, na transformação opaca dos anos 1990. Nasciam assim novos ângulos de inquietação teórica e política.

A questão é tão mais relevante, quanto mais se percebe a centralidade dos temas do trabalho e de formas velhas e novas de seu uso e exploração, para além do assalariamento e do contrato, na discussão da era nebulosa da indeterminação. A Era da Indeterminação (Oliveira; Rizek, 2006) se desdobra e se constitui a partir de nexos e sentidos que se tecem na contramão da possibilidade de liberdade e de escolha - na contramão as possibilidades da política - desenhando a impossibilidade de constituição dos sujeitos sociopolíticos clássicos, em especial dos sujeitos que constituíam seus polos de negatividade. Nesse quadro de indeterminação, na urgência de pensar o presente em suas configurações e transformações, um primeiro caminho foi a longa reflexão centrada no desmanche, expressão tomada de empréstimo de Roberto Schwartz, cuja materialização poderia ser encontrada nas cidades que se transformavam, a olhos vistos, no avesso das possibilidades e dos marcos civilizatórios que se anunciavam, ao menos como expectativa e como possibilidade, desde as lutas pela redemocratização. Esse percurso conduziu Francisco de Oliveira a percorrer um caminho que o levou da análise do desmanche para a análise da ex- 
ceção e da indeterminação, numa reflexão que matizava os percursos do presente ao futuro de modo cada vez mais sombrio ou, em outros termos, como anulação da política pela constituição de um consenso silencioso. A partir do desmanche, outra ordem se desenha - uma ordem cujos nexos ainda exigem reflexão, em que a simples menção da necessidade de políticas públicas universais e universalizantes, aparece como utopia e radicalização. Mais ainda, aquilo que ganhava densidade a partir de conceitos e formas explicativas clássicas, a partir de uma nova elaboração na contramão das vulgarizações da sociologia e do marxismo, parecia exigir um esforço novo de apreensão. A cidade e suas novas formas de segregação, palco de desigualdades que Chico qualifica como abissais, vai se desenhando à luz de uma subjetividade antipública - que habita classes e interesses dominantes - num enorme acampamento, onde os processos de privatização da vida borram os limites entre as promessas de emancipação e novas formas de dominação, entre uma cintilância e sua captura, na explosão de uma violência que resulta de uma "promiscuidade por ausência de relação mercantil que detona os conflitos e leva aos homicídios. Essa ausência tem um nome: desemprego" (Oliveira, 2003b, p. 13).

Se o trabalho esteve, como na Crítica e na discussão das relações entre o Estado e o urbano, no centro da reflexão sobre as cidades, se este quadro de modernização sem a linearidade do progresso conformava a reflexão de 1972, a questão que hoje se coloca é da possibilidade/impossibilidade de sujeitos políticos - ou, pelo menos, das classes sociais como sujeitos políticos - em uma era de indeterminação, isto é, a possibilidade/impossibilidade da experiência de classe ganhar corpo e sentido, conformar seus territórios, seus coletivos e mesmo sua materialidade e concretude. Assim se configuram, primeiro, vulnerabilidades e carências; depois, a pobreza e a pobreza urbana em particular, que nascem da ruptura dos limites entre trabalho formal e informal, emprego e desemprego, de um assalariamento que escapa às formas clássicas do contrato de trabalho, cujo crescimento exponencial aponta, de um lado, outro patamar de produtividade do trabalho e, de outro, a ruptura do solo material, do autorreconhecimento e da organização de classe e, por consequência, conforma os abalos sísmicos nas formas de representação sindical e política.

Se, nos anos 1970-80, foi preciso fazer a crítica da urbanização sem industrialização e substituí-la pela análise da forma autárquica que a indústria nascente conferia às cidades, hoje é preciso fazer a crítica a partir de outro lugar - a potência do capital mundializado em um processo de destituição da forma do assalariamento e do contrato. É preciso reconhecer que o trabalho abstrato ganhou novas formas, uma nova extensão, trabalho sem o solo coletivo da fábrica, ou transformado por contratos que aparecem não como expropriação mas como privilégio. Caem por terra antigas separações, categorias binarizadas e construções conceituais pelas quais se percebia o mundo; o trabalho abstrato, isto é, conformado pela extração de mais valia por todos os poros, para além do assalariamento clássico, estanca a desmercantilização da vida, dilui direitos, institui outras formas de dominação e, no limite, destrói de forma inédita a voz e a presença de classe em opaca indeterminação. ${ }^{10}$

Assim também o urbano se estende, seus limites se borram e a cidade se transforma no seu avesso: lugar da dissolução, da destituição do mundo público, onde a desigualdade se escancara sem provocar escândalo, lugar da privatização da vida e da "desnecessidade do

10 Ver especialmente Oliveira $(2000,2002)$. 
público" mas também lugar de reinvenções, que trazem a possibilidade frágil de novos combates pela distribuição da riqueza, pela restituição do território à elaboração cidadã sempre ameaçada. Em um texto de 2000, F. de Oliveira apostava ainda nessa retomada da invenção democrática - o Orçamento Participativo, para além das oposições entre democracia formal e democracia participativa. $\bigcirc$ que lhe interessava era, sobretudo, a discussão da política como dissenso, do potencial de conflito desmanchando os limites estreitos da gestão, da administração técnica, dos controles estritos da funcionalização da miséria e das políticas sociais restritivas. Interessava, então, a possibilidade de restituir o território da cidade à invenção cidadã, às suas dimensões públicas, por meio de uma reinvenção da política, para além dos marcos normativos e legais.

Experiência política ou controle e confinamento das demandas e movimentos? Reinvenção, território de conflitos, legitimidade das falas, possibilidade de rever e revisitar a cidade, democratizando-a? Tratava-se, então, de perceber, qualificar e mapear suas possibilidades em São Paulo, cujas proporções e problemas, cuja trajetória política eram distintas da experiência mais emblemática do Orçamento Participativo, em Porto Alegre. Mas nada estava garantido na neblina da indeterminação, no jogo incessante de forças entre dominação e emancipação, entre a possibilidade da experiência pública e sua destituição.

Muito rapidamente, um ano e meio depois das Atas da Revolução, Francisco de Oliveira, apontava alguns de seus limites: o sentido territorial, sua circunscrição, talvez até mesmo seu confinamento em contraponto à liberdade extraterritorial das formas de exploração e dominação, das novas formas de acumulação de capital. $\bigcirc$ território, transformado em quase resíduo para as novas formas de acumulação cada vez mais autonomizadas, elemento cuja importância encolhe face à potência das tecnologias da informação, materializando desigualdades de um novo modo, diverso das formas clássicas de segregação socioespacial, já podia ser parcialmente devolvido às disputas da população sem danos às novas formas de gestão e controle compatíveis com os modos mais recentes de acumulação. Democratização ou seu simulacro, a problematização do Orçamento Participativo procurava as pistas deste confronto entre possibilidades de democratização e seu avesso, isto é, entre a possibilidade de refundação da cidade como comunidade política ou mais uma forma em que a participação popular encobriria e ratificaria novas relações entre o urbano e um Estado de exceção que parece se conformar, seguindo as pistas de Benjamin (1940, tese 8), como regra.

Truncamento e inconclusão, incompletude, indeterminação habitaram a reflexão mais recente de Francisco de Oliveira, em que, ainda que tangencialmente, a cidade e a cidade de São Paulo em particular, essa "polis desfigurada", em suas palavras, ganham contorno pela experiência da desigualdade ancorada em um trabalho destituído de arbitragem pública e visível, que desfaz distinções entre emprego formal e informal, emprego e desemprego, com carteira e sem carteira. Talvez aqui seja possível flagrar, pela experiência da cidade, o enigma que confronta modos inéditos de dominação e violência e possibilidades sempre frágeis de publicização e emancipação. A cidade como território onde ganha visibilidade o conflito e os embates que Oliveira caracterizou em outro texto como os trabalhos de Sísifo, se põe como desafio para uma nova decifração. Neste caso, as contradições não se resolvem, rebaixando continuamente seus termos, ainda que novos impasses 
acabem por se colocar, eles também rebaixados em qualidade, ou para usar os termos de Chico, como exceções, ou pequenas exceções. Algo dessa reflexão foi retomada nos termos que se seguem:

[...] As cidades são os lugares por excelência dessas exceções e o conjunto delas é a administração da exceção. Trata-se de um Estado de Exceção, na medida justa da teoria schimittiana, pois o soberano é o que decide a exceção: quem é o soberano? $\bigcirc$ mercado, não como abstração, mas precisamente (como aquilo) que coloca $41 \%$ abaixo da linha de pobreza. Pensemos: o subdesenvolvimento não era a exceção, era uma singularidade histórica que assinalava precisamente que ele havia sido produzido pelo capitalismo em expansão, o qual, montando-se sobre sociedades criadas ou apropriadas para produzir o excedente que na verdade criou o capitalismo mercantil, não poderia, jamais, reproduzir o original [...]. $O$ Ornitorrinco é a exceção permanente, porque já não é singularidade: ele contém todos os elementos do original desenvolvido, já não há espaços pré-capitalistas, já não há fronteiras à expansão do capital. $\bigcirc$ alto desemprego - 20\% em São Paulo não é sinal de desocupação dos fatores [...] mas, ao contrário, acontece por excesso de capitalização. É a cópia do original que causa o desemprego e a péssima distribuição de renda [...]. As políticas chamadas de emprego e renda são a exceção do desemprego [...]. As políticas de mutirões para satisfazer a demanda por habitação são a cidade como exceção; é a desmercantilização da força de trabalho sob a forma do trabalho virtual que prepara o enorme exército "informal" [...] para as portas dos estádios de futebol, ou os arredores dos formosos teatros, ou as bancárias e banqueiras ruas dos centros de nossas cidades. A síntese é a dependência financeira externa do Estado, que come 9\% do PIB como serviço da dívida e equivale a mais da metade do coeficiente de inversão. É a exceção do Estado ou o Estado como exceção (Oliveira, 2003b, p. 12).

Como explicar esse urbano da exceção quando se atribui às pequenas exceções padrões de normalidade? A tarefa da crítica é deslocá-las para uma exceção que amedronta porque ganha dimensões totalizantes já que, por esses mecanismos, a "norma" se rebaixa, acomodando intervenções que se querem publicizantes aos procedimentos que transformam as cidades em territórios de exceção, pelos quais passam os processos de concentração de renda, os novos modos de separação socioterritorial que isolam e expulsam "a sociabilidade indesejável das classes 'perigosas', o controle policial, as altas taxas de homicídios, ou seja, as cidades são o território onde ganha materialidade e visibilidade o retrato sem retoques de uma sociedade derrotada" (Oliveira, 2003b, p. 13).

Como territórios da exceção, as cidades se redesenham à luz de uma guerra civil mal disfarçada. Talvez sejam a expressão mais clara de uma violência que se origina da dissolução da política, do conflito e de sua experiência no solo e no reconhecimento coletivo dos sujeitos políticos. A violência da indeterminação não é a violência pura, a violência da negatividade e da possibilidade de transformação. Ao contrário, essa violência é, para F. de Oliveira, o terreno pantanoso que se produz pela dissolução dos sujeitos do conflito político, pela dissolução da invenção da política. 
O chiste final desse texto, carregado de ironia e de crítica, aponta mais uma vez a tarefa de uma reflexão que se recusa ao silêncio. Ironia e luto se combinam no uso de uma linguagem ácida, espinhosa, dura e necessária, voltada para o que se silenciou nas novas e eficientes formas de assimilação que conformam o real como única alternativa, como um eterno menos pior.

Não há mais política: há tecnicidades e dispositivos [...] que se impõem com a lei da necessidade. Adequamos nosso discurso para reconhecer a "realidade" e em nome dela, planejar a exceção. Reconheçamos: nosso esforço teórico transitou da busca da normatividade para a racionalização da exceção, que nossa prática cotidiana já leva a cabo faz tempo. Porque do nosso horizonte já sumiram as transformações. Sejamos pragmáticos, já é tempo e já estamos na idade, ora bolas, de abandonar as utopias!

\section{Considerações finais}

Crítica, desassossego e coragem se traduzem em paixão pela política como invenção, pela denúncia implacável dos modos pelos quais novas formas de dominação se anunciam, no interior daquilo mesmo que poderia conduzir o combate e a reflexão a seu compromisso com a emancipação. Pensar, assumir o lugar da crítica implacável, com todo o seu desconforto, o lugar de uma razão que não se conforma com o mundo e tampouco o justifica, oferece poucas respostas, sobretudo quando pensar e escrever é visto como luta contra a banalização, a simplificação e a vulgarização. Pois é, Chico, o que se pôde ver em todos e em cada um desses momentos foi uma batalha em cada texto, um texto em cada batalha, numa reflexão que detecta o perigo da recomposição da dominação ali mesmo onde se poderia entrever seu esmorecimento, seu encolhimento.

Na sua radicalidade, na batalhas contra as formas de dominação de classe, contra a opacidade desses modos de dominação, contra o encolhimento do mundo e da política, na inquietação de quem nunca parou de brigar, os textos de Chico de Oliveira anunciaram a cada momento a construção de um modo de olhar o mundo, a política, o conflito e as expressões da luta de classes a partir da realidade brasileira. Sua perspectiva crítica incansável se voltava a compreender e entender esse ornitorrinco chamado Brasil, para além de toda censura, com a coragem imposta por cada momento de sua vida e de sua produção.

Esperamos, querido amigo e querido mestre, estar à altura da herança crítica tecida em cada um de seus combates, vistos como registro e análise da difícil e intrincada formação e desmanche do que um dia pudemos coletivamente inventar e reconhecer como um país. Talvez relendo seus textos possamos superar os muitos lutos e perdas que se desenham num presente cheio de sombras. Talvez tenhamos que aprender e reaprender mais uma vez com o tesouro crítico que nos deixou, fazendo-o ressoar de novo no mundo. Afinal, como advertiu Benjamin (1940, tese 3), "nada do que um dia aconteceu pode ser perdido para a história".

\section{Referências}

BENJAMIN, W. Teses sobre o conceito da história, 1940. Disponível em : https://edisciplinas. usp.br/pluginfile.php/3957253/mod_resource/content/1/Teses\%20sobre\%20॰\%20 conceito\%20de\%20hist\%C3\%B3ria\%20\%281\%29.pdf. Acesso em 21 ago. 2019. 
FURTADO, C. Formação econômica do Brasil. São Paulo: Companhia das Letras, 2009[1959]. Edição Comemorativa de 50 anos.

OLIVEIRA, F. Crítica à razão dualista/O ornitorrinco. São Paulo: Boitempo, 2003a.

OLIVEIRA, F. O Estado e a exceção ou o Estado de exceção?. Revista Brasileira de Estudos Urbanos e Regionais, v. 5 , n. 1, p. 9-14, maio 2003b.

OLIVEIRA, F.O trabalho abstrato e as novas formas de conflito (entrevista). In: LOUREIRO, I.; LEITE, J. C.; CEVASCO, M. E. (Org.). O espírito de Porto Alegre. São Paulo: Paz e Terra, 2002. p. 91-106.

OLIVEIRA, F. Passagem na neblina. In: OLIVEIRA, F; GENOÍNO, J.; STÉDILE, J. P. Classes sociais em mudança e a luta pelo socialismo. São Paulo: Fundação Perseu Abramo, 2000. p. 7-22.

OLIVEIRA, F. Os direitos do anti-valor. Petrópolis, RJ: Vozes, 1998.

OLIVEIRA, F. O Estado e o urbano no Brasil. Espaço e Debates, v. 2, n. 6, p. 36-54, 1982.

OLIVEIRA, F; PAOLI, M. C.; RIZEK, C. Atas da Revolução: o orçamento participativo em São Paulo. Democracia Viva, Rio de Janeiro, 2000. Disponível em: www.ibase.org.br. OLIVEIRA, F; PAOLI, M. C. Os sentidos da democracia. Petrópolis, RJ: Vozes, 1999.

OLIVEIRA, F; RIZEK, C. S. (Org.). A Era da Indeterminação. São Paulo: Boitempo, 2006. SINGER, P. I. O "milagre brasileiro": causas e consequências. São Paulo: Cebrap, 1972. 